[0212-7199 (2008) 25: 5; pp 234-236] ANALES DE MEDICINA INTERNA Copyright (C) 2008 ARAN EDICIONES, S.L.

An. MEd. INTERNA (Madrid) Vol. 25, N. ${ }^{\circ}$ 5, pp. 234-236, 2008

\title{
Engrosamiento traqueobronquial producido por herpesvirus en un paciente con síndrome de Good
}

\author{
A. FERNÁNDEZ-VILLAR, J. L. GARCÍA-TEJEDOR', V. LEIRO FERNÁNDEZ, \\ M. BOTANA RIAL, A. MÉNDEZ GARRIDO, E. RIVO VÁZQUEZ ${ }^{2}$, C. VILARIÑO \\ $\mathrm{POMBO}^{3}$
}

Servicios de Neumología, ${ }^{1}$ Radiodiagnóstico y ${ }^{2}$ Cirugía Torácica. Hospital Xeral. CHUVI. Vigo. ${ }^{3}$ Servicio de Neumología. Hospital Montecelo. CHOP. Pontevedra

TRACHEOBRONCHIAL WALL THICKENING SECONDARY TO HERPESVIRUS INFECTION IN A PATIENT WITH GOOD SYNDROME

\begin{abstract}
RESUMEN
Se decribe el caso de un paciente con síndrome de Good (timoma e hipogammaglobulinemia), que estando oligosintomático, se le realizó una tomografía computerizada de tórax de control en la que se evidenció un engrosamiento circunferencial de la pared traqueobronquial. Una broncoscopia demostró datos de una traqueobronquitis con áreas necróticas y vesículo-ampollosas, siendo los hallazgos histopatológicos y de inmunohistoquímica compatibles con una infección por el virus del herpes simple. La respuesta terapéutica al aciclovir oral fue satisfactoria.
\end{abstract}

PALABRAS CLAVE: Síndrome de Good. Engrosamiento traqueobronquial. Traqueobronquitis. Virus de herpes simple.

\begin{abstract}
We describe an oligosymptomatic patient with Good syndrome (thymoma and hypogammaglobulinemia) in who a follow-up chest computed tomography showed circumferential tracheobronchial wall thickening. Bronchoscopy demonstrated tracheobronchitis with necrotic, vesicular and blister areas. The histopathological and immunohistochemical findings were compatible with herpes simplex virus infection. The therapeutical response to oral acyclovir was satisfactory.
\end{abstract}

KEY WORDS: Good syndrome. Tracheobronchial wall thickening. Tracheobronchitis. Herpes simplex virus.

Fernández-Villar A, García-Tejedor JL, Leiro Fernández V, Botana Rial M, Méndez Garrido A, Rivo Vázquez E, Vilariño Pombod C. Engrosamiento traqueobronquial producido por herpesvirus en un paciente con síndrome de Good. An Med Interna (Madrid) 2008; 25: 234-236.

\section{INTRODUCCIÓN}

El síndrome de Good (timoma e hipogammglobulinemia) es una causa rara de inmunodeficiencia en adultos (1-3). Las características clínicas y las complicaciones de este síndrome se relacionan fundamentalmente con las derivadas de una elevada susceptibilidad a infecciones bacterianas, víricas y fúngicas (13). Hasta el momento no se han descrito casos de afectación del árbol traqueobronquial por virus de herpes simple (VHS) en este tipo de pacientes (3). Presentamos el caso de un paciente diagnosticado de síndrome de Good en el que en un estudio radiológico de control, y estando oligosintomático, se encontró un engrosamiento difuso de la traquea y ambos bronquios principales. Una broncoscopia permitió confirmar estos hallazgos y realizar el diagnóstico etiológico de traqueobronquitis por el VHS. Describimos este caso debido a que en él se suman varias circunstancias que lo hacen excepcional.

\section{CASO APORTADO}

Paciente varón de 60 años diagnosticado de síndrome de Good tres años antes. Se realizó en ese momento timectomía, siendo el resultado anatomopatológico según la clasificación de la OMS (4) de timoma tipo $\mathrm{AB}$. Debido a que esta resección no fue completa recibió posteriormente radioterapia (dosis acumulada $50 \mathrm{~Gy}$ ). El paciente había sido fumador de más de 20 paquetes-años y bebedor de unos $60 \mathrm{~g} /$ día hasta ese momento. Había sido hospitalizado en múltiples ocasiones en otros centros hospitalarios por infecciones respiratorias, algunas de ellas neumónicas, y diagnosticado de colitis por citomegalovirus, aplasia medular y otras complicaciones relacionadas con los cuadros previos. Recibía tratamiento con dosis profilácticas de trimetropín-cotrimoxazol, broncodilatadores, omeprazol y administración i.v. mensual de inmunoglobulinas polivalentes. En una TC torácica de seguimiento se evidenció un engrosamiento circunferencial de la pared de la traquea, fundamentalmente a nivel de su mitad caudal, y de ambos bronquios principales, y que producía en algún nivel una marcada estenosis de la luz (Figs. 1). En ese momento no había presentado fiebre o lesiones cutáneas, aunque si refería un incremento leve de su tos, expectoración y disnea habituales. La exploración física fue normal. En la analítica sanguínea presentaba una anemia y leucopenia muy discretas, una VSG de $32 \mathrm{~mm}$ y una proteína $C$ reactiva de $0,5 \mathrm{mg} / \mathrm{dl}$. El resto de parámetros bioquímicos y de hematimetría estaban dentro de los límites normales. Los niveles de inmunoglobulinas eran bajos, con una IgG de 308 $\mathrm{mg} / \mathrm{dl}, \operatorname{IgA}<7 \mathrm{mg} / \mathrm{dl}$ y una $\operatorname{IgM}<4 \mathrm{mg} / \mathrm{dl}$. Se realizó una fibrobroncoscopia con sedación consciente con midazolam i.v. en la que se objetivó un engrosamiento difuso de toda la mucosa traqueal y de ambos bronquios principales de apariencia inflamatoria con áreas de aspecto necrótico y vesiculoampollosas (Fig. 2). No se evidenciaron lesiones a nivel faríngeo o laríngeo. Se realizaron biopsias a varios niveles, en las que la mucosa traqueobronquial presentaba una ulceración de la superficie constituida por un material fibrinonecrótico, por debajo de la cual existía un tejido de granulación con inflamación mixta. Con técnicas de inmunohistoquímica para herpesvirus I y II se observó una intensa expresión nuclear en las células escamosas de las zonas descritas, siendo negativas las realizadas para citomegalovirus. El paciente recibió tratamiento oral con aciclovir (400 mg 5 veces/día) durante 10 días, con

Trabajo aceptado: 14 de enero de 2008 

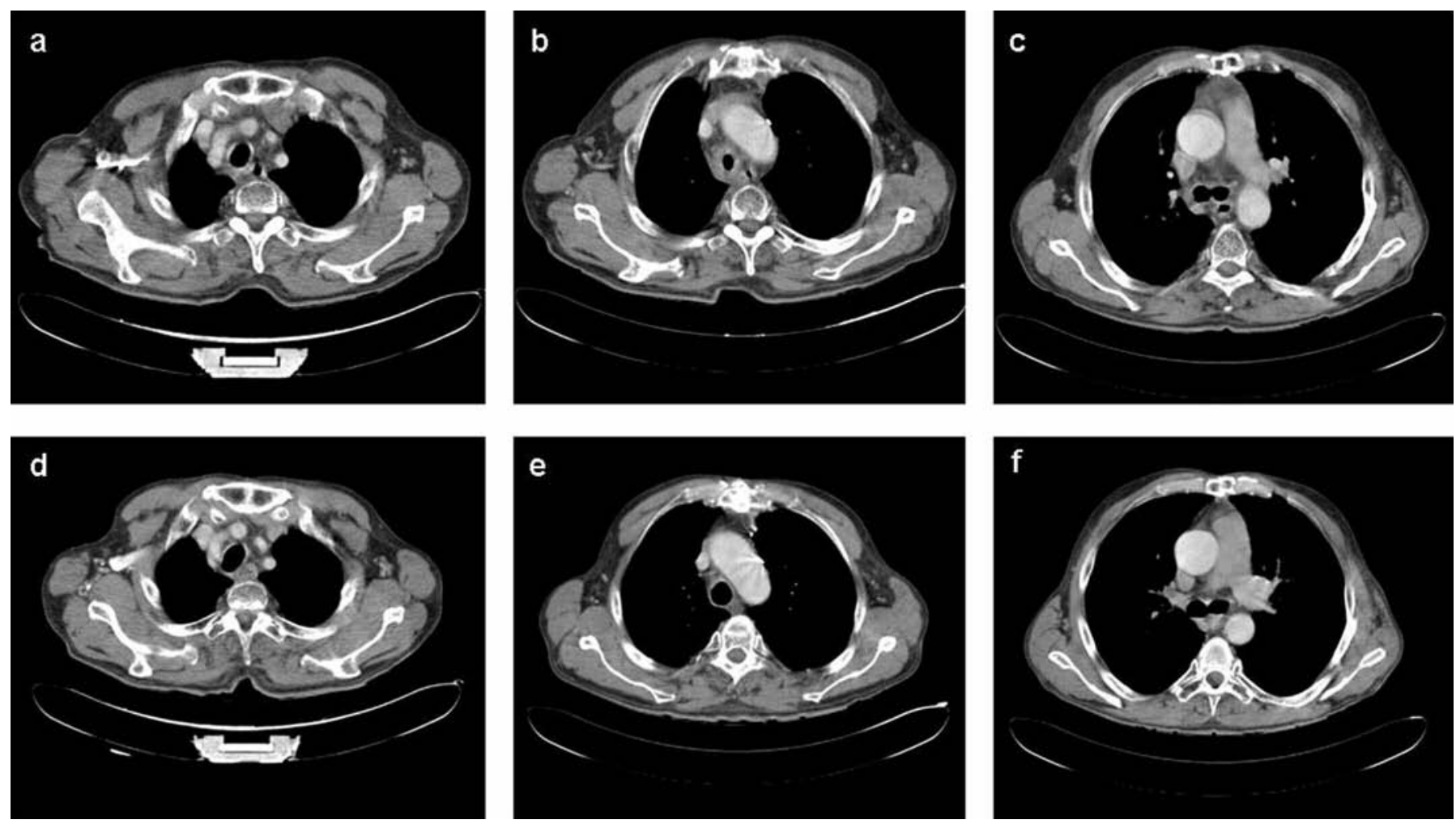

Fig. 1. Cortes de TC torácica que muestran un engrosamiento circunferencial de la pared traqueobronquial ( $a$, b y c), con una marcada estenosis de la luz en algunos de los cortes (b) y desaparición de dichos hallazgos tras tratamiento con aciclovir (d, e y f).

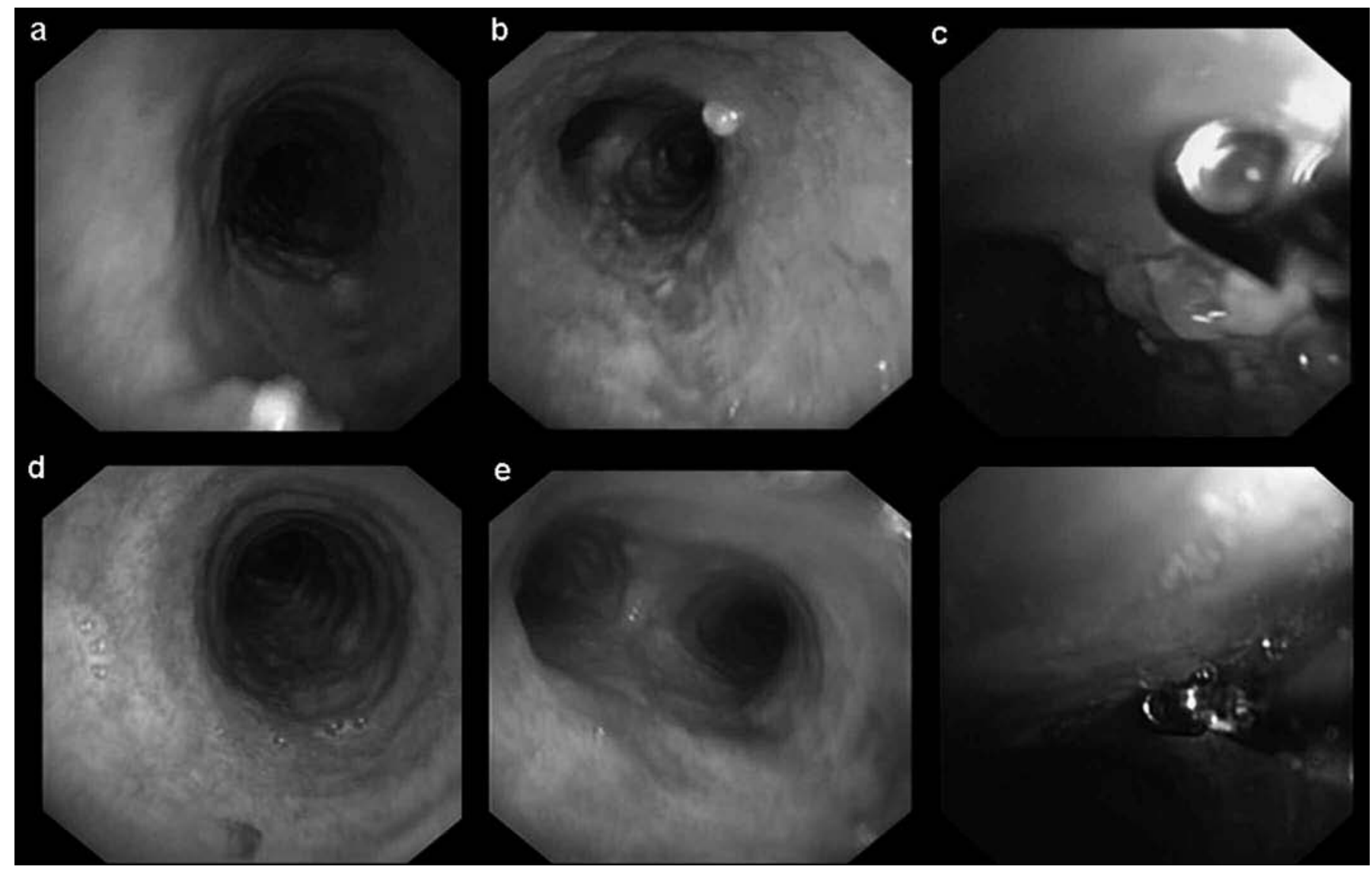

Fig. 2. Imágenes broncoscópicas en las que se observa una mucosa traqueobronquial de aspecto inflamatorio con áreas vesiculoampollosas $(a, b$ y c) y la mejoría de estas lesiones tras tratamiento con aciclovir (d, e y $f$ ). 
excelente tolerancia. En una TC (Fig. 1) y una fibrobroncoscopia (Fig. 2) realizadas cuatro semanas después de finalizar el tratamiento las lesiones descritas inicialmente se habían resuelto. Las biopsias que se llevaron a cabo en los mismos niveles revelaron una mucosa normal.

\section{DISCUSIÓN}

El síndrome de Good es una rara entidad de etiología desconocida que se caracteriza por la asociación de timoma e inmunodeficiencia debida fundamentalmente a un déficit en el número de linfocitos B periféricos, hipogammglobulinemia y alteraciones en la inmunidad celular (1-3). También, y al igual que en nuestro caso se han descrito otras complicaciones como aplasia medular, anemia, leucopenia y miastenia gravis (1). Los timomas suelen ser benignos y encapsulados, aunque las alteraciones inmunológicas no suelen revertir tras su extirpación quirúrgica. Cuando ésta no es posible, o la resección es incompleta, está indicada la radioterapia (2). Característicamente los pacientes presentan una elevada susceptibilidad a infecciones por bacterias, hongos y virus (1-3). Estas suelen ser infecciones sinopulmonares recurrentes, mucocutáneas, oftálmicas, encefálicas, gastrointestinales y del tracto urinario. Los gérmenes implicados con más frecuencia suelen ser bacterias como Haemophilus influenzae, Klebsiella y Pseudomona spp, Giardia lamblia, Salmonella spp, Campylobacter jejuni, virus como citomegalovirus o VHS, hongos como Candida albicans y Pneumocistis jirovecii, y excepcionalmente protozoos como Babesia (1-3,5). Tras consultar la base de datos Medline (National Lybrary of Medicine) utilizando las palabras clave "Good syndrome, thymoma, hypogammaglobulinemia, immunodeficiency and infection", únicamente hemos encontrado 4 casos de afectación herpética, recogidos ya por Tarr y cols. (3) en su exhaustiva revisión. En ninguno de ellos se describía una afectación del árbol traqueobronquial, por lo que el presente caso puede ser el primero reportado de una traqueobronquitis por VHS en un paciente con síndrome de Good. La traqueobronquitis herpética ha sido descrita en pacientes con otros tipos de inmunodepresión, grandes quemados, pacientes con graves enfermedades crónicas, pacientes críticos ventilados mecánicamente y excepcionalmente en pacientes previamente sanos (6-8). Su patogenia no se conoce con claridad, aunque existe evidencia que el virus puede introducirse en la vía respiratoria mediante la intubación traqueal en pacientes ventilados (7). También se piensa que podría producirse por una reactivación de una infección herpética preexistente a

\section{Bibliografía}

1. Agarwal S, Cunningham-Rundles $\mathrm{C}$. Thymoma and immunodeficiency (Good syndrome): A report of 2 unusual cases and review of the literature. Ann Allergy Asthma Immunol 2007; 98: 185-90.

2. Kelleher P, Misbah SA. What is a Good's syndrome? Immunological abnormalities in patients with thymoma. J Clin Pathol 2003; 56: 12-6.

3. Tarr PE, Sneller MC, Mechanic LJ, Economides A, Eger CM, Strober $\mathrm{W}$, et al. Infections in patients with immunodeficiency with thymoma (Good syndrome). Report of 5 cases and review of the literature. Medicine (Baltimore) 2001; 80: 123-33.

4. Kondo K, Yoshizawa K, Tsuyuguchi M, Kimura S, Sumitomo M, Morita J, et al. WHO histologic classification is a prognostic indicator in thymoma. Ann Thorac Surg 2004; 77: 1183-8.

5. Jian L, Bin Du, Hayyun W. Fatal Pneumocystis pnemoniae with Good syndrome and pure red cell aplasia. Clin Infec Dis 2004; 39: 1740-1.

6. Bruynseels P, Jorens PG, Demey HE, Goossens H, Pattyn SR, Elseviers MM, et al. Herpes simplex virus in the respiratory tract of critical care patients: a prospective study. Lancet 2003; 362: 1536-41.

7. Baras L, Farber CM, Van Vooren JP, Parent D. Herpes simplex virus nivel del nervio vago $(7,8)$. Las características clínicas, radiológicas y el pronóstico no son bien conocidos, ya que el mayor número de casos publicados ha sido de pacientes críticos con ventilación mecánica invasiva y múltiples comorbilidades y complicaciones pulmonares, por lo que éstas podrían superponerse. En el resto de casos publicados, éstas han sido muy variables (6-10). No suelen, al igual que en nuestro caso, objetivarse lesiones orales (8-10). En muchos de los casos reportados se detectan alteraciones parenquimatosas compatibles con neumonía (10). Aunque se ha descrito lesiones obstructivas pseudotumorales de la vía aérea por herpes virus $(8,9)$, no hemos encontrado casos publicados en los que se evidenciara un engrosamiento difuso de la pared traqueobronquial en la TC de tórax. De hecho, en tres recientes artículos en los que se revisan las patologías no neoplásicas que pueden producir un engrosamiento difuso de la pared traqueobronquial, la afectación por herpes virus no se menciona (11-13). Las entidades citadas en el diagnóstico diferencial de este tipo de hallazgo en la TC son la Granulomatosis de Wegener, la policondritis recidivante, la amiloidosis, la traqueobroncopatía osteocondroplástica, la traqueobronquitis asociada a enfermedades inflamatorias intestinales y la sarcoidosis, siendo las únicas etiologías infecciosas referidas la papilomatosis laringotraqueobronquial, la tuberculosis y el rinoescleroma (11-13).

El diagnóstico suele hacerse por los hallazgos de la fibrobroncoscopia, en conjunción con la citología, cultivos y hallazgos histológicos de las biopsias (6-10), aunque las técnicas más sensibles incluyen la detección por técnicas inmunohistoquímicas de antígenos virales (8), técnica diagnóstica en el presente caso. La afectación traqueobronquial por VHS produce una inflamación difusa de la mucosa, con eritema, edema y presencia de vesículas y ulceraciones y raramente lesiones obstructivas pseudotumorales (7-9).

La respuesta al tratamiento es variable, dependiendo de las comorbilidades, la situación general del paciente en el momento del diagnóstico y la rapidez de instauración del tratamiento (6-10). En nuestro caso, la respuesta al aciclovir oral fue muy favorable con resolución completa de las lesiones radiológicas y endoscópicas y normalización de los hallazgos histológicos.

En conclusión, pensamos que el diagnóstico diferencial del hallazgo de un engrosamiento traqueobronquial difuso en un paciente inmunodeprimido debe incluir la posibilidad de una infección por el VHS y ser confirmada mediante broncoscopia. tracheitis in a patient with the acquired immunodeficiency syndrome. Eur Respir J 1994; 7: 2091-3.

8. Upadya A, Tilluckdharry L, Nagy CD, Ravichandran P, Manthous C. Endobronchial pseudo-tumour caused by herpes simplex. Eur Respir J 2005; 25: 1117-20.

9. St John RC, Patch E. Tracheal stenosis and failure to wean from mechanical ventilation due herpetis tracheitis. Chest 1990; 98: 1520-2.

10. Morrondo Valdeolmillos P, Azkárate Ayerdi B. Neumonía nosocomial por virus de herpes simple tipo I. Med Intensiva 2001; 25: 208-10.

11. Prince JS, Duhamel DR, Levin DL, Harrell JH, Friedman PJ. Nonneoplastic lesions of the tracheobronchial wall: Radiologic findings with bronchoscopic correlation. Radiographics 2002; 22 (Sup1.): 215-30.

12. Elicker BM, Leung JWT, Reddy GP, Gotway MB. Diffuse tracheobronchial thickening. Interesting diagnostic considerations. Clin Pulm Med 2006; 12: 216-9.

13. Del Grande P, Russi EW, Hailemariam S, Hauser M. Extensive tracheobronchial wall thickening and luminal narrowing in a patient with longstanding hoarnseness. Respiration 2002; 69: 186-90. 